\title{
Investigation of the change in soil fabric during cone penetration in silt using 2D measurements
}

\author{
Priscilla Paniagua $^{1,3}$ (D) $\cdot$ Joana Fonseca $^{2} \cdot$ Anders Gylland $^{1} \cdot$ Steinar Nordal $^{1}$
}

Received: 4 October 2016/Accepted: 2 May 2017/Published online: 19 May 2017

(C) The Author(s) 2017. This article is an open access publication

\begin{abstract}
Interpretation of CPTU testing in silt is nontrivial because of the partially drained conditions that are likely to occur during penetration. A better understanding of the pore pressure generation/dissipation is needed in order to obtain reliable design parameters. Following a previous study using X-ray computed tomography (microCT) with volumetric digital image correlation (3D-DIC) that clearly showed the formation of distinct dilation and compression areas around the cone; the present work takes a closer look at those areas in order to link volumetric behavior to changes in soil fabric. High-resolution 2D backscattered electron images of polished thin sections prepared from frozen samples at the end of penetration are used. The images have a spatial resolution of $0.4 \mu \mathrm{m} / \mathrm{pixel}$ that allow a clear identification of grains and pore spaces. Image processing techniques are developed to quantify local porosity and obtain the statistical distribution of the particle orientation for the zones around the cone tip and shaft. It is shown that the formation of compaction regions is related to the ability of the grains to rearrange and align along a well-defined preferred orientation forming a more
\end{abstract}

Priscilla Paniagua

priscilla.paniagua.lopez@ngi.no

Joana Fonseca

joana.fonseca.1@city.ac.uk

Anders Gylland

anders.gylland@multiconsult.no

Steinar Nordal

steinar.nordal@ntnu.no

1 Norwegian University of Science and Technology (NTNU), Trondheim, Norway

2 City University of London, London, UK

3 Norwegian Geotechnical Institute, Trondheim, Norway closed-fabric characterized by high anisotropy values, while zones of dilation are associated with a more open packing with grains randomly oriented and with large voids within. These observations suggested that for a saturated soil, water will move from a compressive zone to a neighboring dilative zone, creating a short drainage path. By shedding light on the link between soil fabric and drainage patterns, this study contributes toward a better understanding of the measured macro-response during CPTU tests on silt.

Keywords Cone penetration test - Deformation - EPMA Particle orientation · Porosity - Silt · Thin section

\section{Introduction}

The term silt or intermediate soil covers granular materials with grain size somewhere between clay and sand. The specified range size for silt varies and that reflects the uncertainty associated with the material. The range 2-60 $\mu \mathrm{m}$ [5] is often used for convenience and simplicity. The Norwegian Geotechnical Society [20] classifies silt as the material for which $45 \%$ of its mass is in the range of 2-63 $\mu \mathrm{m}$ and less than $15 \%$ of the material has size lower than $2 \mu \mathrm{m}$, while the AASHTO [11] uses the range 5-75 $\mu \mathrm{m}$. Curiously, only the unified soil classification system [2] includes the plasticity properties for the soil classification: silt being defined as soil passing the $75 \mu \mathrm{m}$ sieve (more than $85 \%$ passing) and showing a plasticity index lower than $4 \%$.

In terms of mechanical behavior, silt falls into the classification of transitional soil with a mode of behavior between that of clean sands and plastic clays. A consistent 
set of soil characteristics associated with transitional behavior cannot be easily established, and this leads to difficulties in predicting soil behavior directly from the soil characteristics [35]. LeBlanc and Randolph [13] suggest that the shear strength properties of silt are comparable to those of sand and that the volumetric properties are analogous to those of clays. In particular, for CPTU tests on silt, penetration may occur under partially drained conditions [15]. This hampers interpretation of results since conventionally CPT tests are based on either drained or undrained behavior. Typical failure mechanisms from undrained triaxial tests on silt have shown distinct dilative and contractive responses (e.g., [25]). The dilative failure mechanism is characterized by a tendency of volume increase under high shear stress, which causes a reduction in the pore pressure toward suction, in saturated samples. The contractive response results from a volume reduction and is accompanied by an increase in pore pressure when approaching failure. The dilative behavior has been associated with dense samples and contractive behavior associated with loose to medium dense samples of silt. Yang [38] and Long et al. [14] have highlighted the role of fines in controlling the volumetric behavior of the material. According to these studies, silts with high percentage of fines will tend to have a dominant contractive behavior, which can be linked to the fact that those samples also exhibit higher density. Paniagua et al. [27] have shown that both contractive and dilative behavior can actually coexist in the same specimen. The authors have carried out laboratory scale CPT tests on Vassfjellet silt and using X-ray micro-CT together with volumetric digital image correlation (3D-DIC) analyses have shown the formation of two distinct bulb-shaped zones under the tip of the cone: a compaction and a dilation zones, respectively (Fig. 1). These observations suggest that the failure mechanism is likely to be more than just a uniform plastic reshaping and raises the question: what are the mechanisms taking place at the grain scale that originate this volumetric behavior?
Image-based techniques at the grain scale constitute a powerful way of gaining understanding into the complex behavior of soil. A number of experimental and numerical studies have repeatedly demonstrated that the mechanical behavior is sensitive to the soil fabric, defined here as the arrangement of the grains and pore spaces in the soil according to Mitchell and Soga [17]. Fonseca et al. [8, 9] have shown that the differences in response between intact and reconstituted specimens of a silica sand could be explained based on differences in the initial fabric and the way this fabric evolves under loading. The authors have quantified the orientation of the grains, the orientation of the contact normal and orientation of the voids and observed their changes under shearing. Andò et al. [1] have measured grain rotation also during shearing of a silica sand and related it to the formation of the shear band in the specimen. Soil fabric and the mode it evolves under an imposed deformation are directly affected by grain morphology. Irregularly shaped grains, in particular, elongated grains are more likely to hinder grain rotation and the capacity for rearrangement which affects the level of dilation [6, 30]. Nouguier-Lehon et al. [21] pointed out the significant effect that the direction of loading relative to the direction of the initial fabric has on specimens made of elongated particles. Oda et al. [23] has identified the preferable alignment of non-spherical particles as one of the primary sources of anisotropy in soil. Lupini et al. [16] has reported the bias in the reorientation of the more elongate flaky grains under imposed deformation.

This study aims to improve our understanding of CPTU testing in silt by investigating the soil fabric after deformation caused by cone penetration. Studies at the grain scale have been, for the most part, limited to sand-sized material; image analysis of silt poses further challenges due to the small grain size and also due to the wide range of shapes and sizes of the mixing. Image analysis techniques were developed here to measure grain orientation and local porosity, and infer the grain-scale mechanisms associated
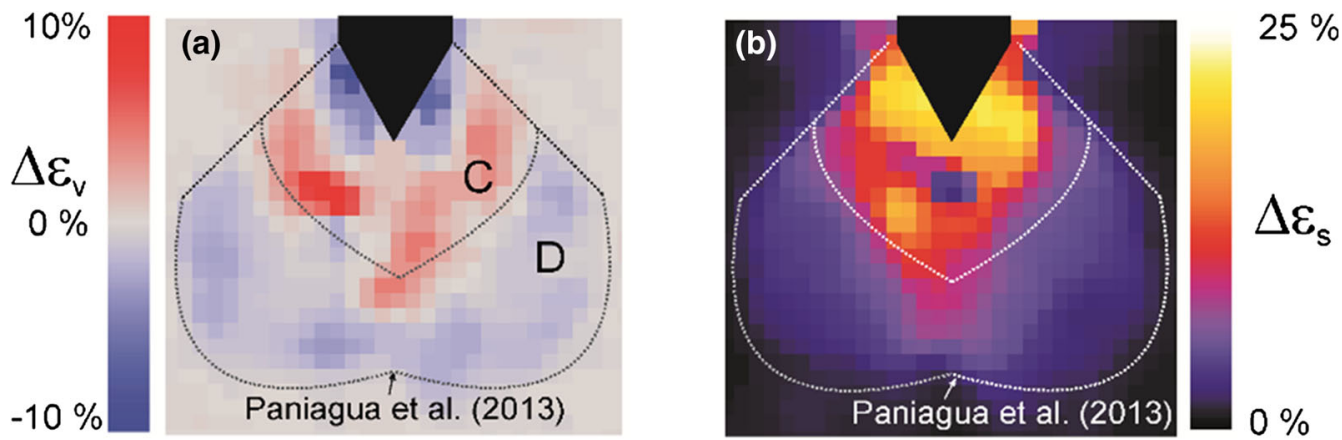

Fig. 1 a Incremental volumetric strains and b incremental shear strains for a penetration increment of $5 \mathrm{~mm}$ (Paniagua et al. [27]). C: compaction and D: dilation 
with the formation of the contractive and dilative zones around the penetrating probe.

\section{Soil description and experimental methods}

\subsection{Vassfjellet silt}

The silt investigated here is a non-plastic uniform silt from Vassfjellet, Klæbu, in Norway. The silt was deposited at a time when the ice sheet remained in its most southerly position around 10,600 years ago. Silty deposits were transported by melted water from the ice sheet that eroded rocks and accumulated them in the glacier front [32]. In general, these deposits infilled natural topographical depressions forming relatively horizontal terraces [14].

Vassfjellet silt has $94 \%$ of its grains with a size lower than $74 \mu \mathrm{m}$ and a clay content of $2.5 \%$. The material has a maximum void ratio of 1.46 , obtained by allowing the slurry to settle in a graduated cylinder [4]. In addition, it has a minimum void ratio of 0.56 , obtained by the modified compaction method for fine grained soils [36] which resembles a Proctor compaction test.

A maximum dry density $\left(\rho_{\mathrm{d}-\mathrm{max}}\right)$ of $1,6 \mathrm{~g} / \mathrm{cm}^{3}$ was found at $23 \%$ optimum water content and $95 \%$ saturation. High dilatant behavior was observed in samples tested in undrained triaxial tests (isotropic consolidated) at its maximum density and the friction angle, $\varphi$,' measured was of $32^{\circ}$ [12]. The mineralogical analysis using X-ray powder diffraction (XRD) showed a composition of 35\% muscovite, $27 \%$ quartz, $18 \%$ chlorite, $15 \%$ feldspar and $5 \%$ actinolite. A backscattered electron image from an electron probe micro-analysis (EPMA) scan of the Vassfjellet silt is presented in Fig. 2. The large grains are mainly composed of quartz and feldspars and tend to have a bulky shape. The smaller and more elongated grains tend to be formed of

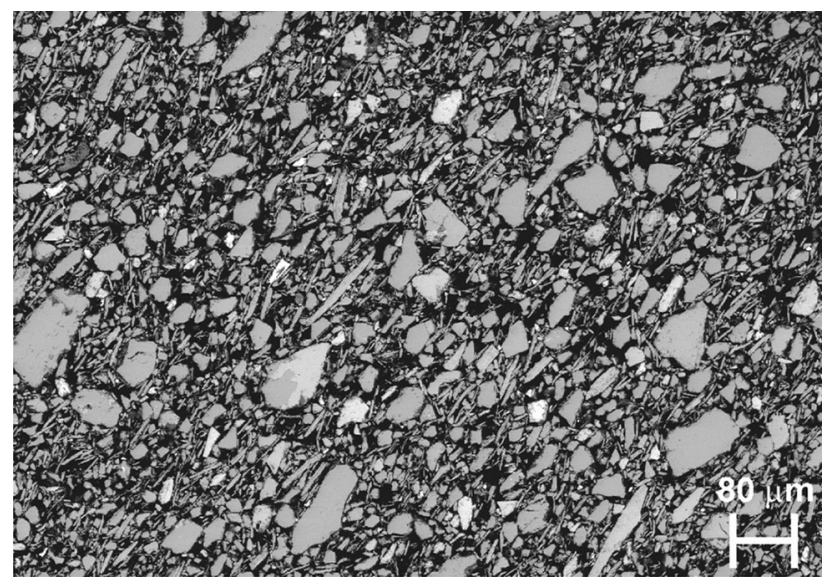

Fig. 2 Backscattered electron image from EPMA scan of the Vassfjellet silt phyllosilicates such as muscovite, chlorite and actinolite and have a flaky structure.

\subsection{The cone penetration test}

The cone penetration test (CPT) is a field test which consists on pushing a cone on the end of a cylindrical probe into the ground. The conventional probe diameter is $35.7 \mathrm{~mm}$, and the conventional pushing rate is $20 \mathrm{~mm} / \mathrm{s}$. Measurements of cone tip resistance to penetration and shaft friction are recorded. When in addition the pore water pressure is measured behind the cone shoulder $\left(\mathrm{u}_{2}\right.$ position), the test is called CPTU. The objectives of the test are to identify soil material layering and geotechnical parameters for design. Interpretation methods for CPT or CPTU, using continuum mechanics concepts, are based on one of two extremes: drained behavior in sands and undrained behavior in clay.

\subsection{Test set-up and equipment}

Three cone penetration tests were carried out as summarized in Table 1. For each test, the soil sample was built inside a Plexiglas cylinder, two diameters of, respectively, 140 and $245 \mathrm{~mm}$, were used (Fig. 3a). The Plexiglas cylinder was internally padded with a layer of neoprene padding with thickness varying between 25 and $40 \mathrm{~mm}$. The paddings were used to compensate for the effect of the boundary closeness and account for the compressibility of the surrounding soil. The thickness and padding stiffness values were obtained from finite element (FE) calculations of an expanding cavity in silt with a cavity diameter equal to the sample diameter (more details can be found in Paniagua et al. [27].

The specimens were prepared by the modified moist tamping (MMT) method [4] and saturated from the bottom up to air bubbles formation layer. The samples had a dry density $\left(\rho_{d}\right)$ of $1.4 \mathrm{~g} / \mathrm{cm}^{3}$, a relative density $\left(D_{r}\right)$ of $60 \%$ and a water content of $47 \%$. After preparation, the samples for tests MMT02 and MMT03 were preloaded using a top load of $40 \mathrm{kPa}$, which was kept constant during testing. The test MMT01 was carried out without preloading the soil.

Table 1 Characteristics of the three tests carried out

\begin{tabular}{llll}
\hline Test parameters & MMT01 & MMT02 & MMT03 \\
\hline Top pressure $p_{0}{ }^{\prime}(\mathrm{kPa})$ & 0 & 40 & 40 \\
Cone diameter dc $(\mathrm{mm})$ & 35.7 & 35.7 & 20.0 \\
Soil cylinder diameter $(\mathrm{mm})$ & 220 & 220 & 100 \\
Plexiglas cylinder diameter $(\mathrm{mm})$ & 245 & 245 & 140 \\
\hline
\end{tabular}




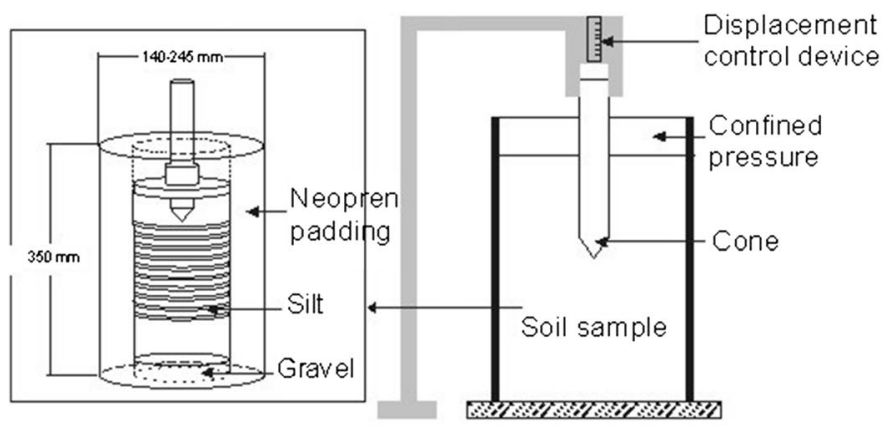

(a)

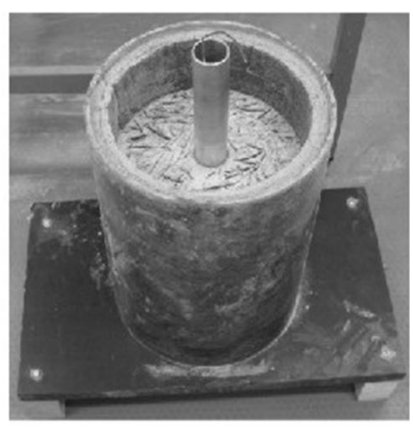

(b)

Fig. 3 a Experimental set-up and b picture of a frozen sample

Aluminum cones with $60^{\circ}$ apex angle and diameters of 35.7 and $20 \mathrm{~mm}$, respectively, were used. Each sample was progressively penetrated by the cone at a standard rate of $20 \mathrm{~mm} / \mathrm{s}$. The penetration was done down to $15 \mathrm{~cm}$ using a conventional loading apparatus. Measurements of cone resistance were limited due to equipment constrains. The expected penetration force was of approximately $100 \mathrm{~kg}$ for the samples with a $40 \mathrm{kPa}$ preload and $30 \mathrm{~kg}$ for the sample without preloading. No particle breakage is expected to occur for the current level of penetration force.

Following probe penetration, the samples were frozen at a temperature of $-20{ }^{\circ} \mathrm{C}$ with the cone inside (Fig. 3b). The process was carried out at the NTNU Ice Laboratory, following the technique proposed by Paniagua et al. [26]. This technique permits removing the molding forms and the cone afterward. The cone was removed by heating carefully the aluminum and making sure that the soil was not melted around it. Subsequently, the frozen samples were cut through its center. After sample cutting, the frozen blocks were carefully oven-dried based on a previous evaluation of drying techniques (i.e., room temperature drying and oven drying). Oven drying produced samples with the highest resistance against mechanical actions and the highest success rate when preparing the thin sections. Although some grain reorientation and compaction may be introduced using this approach $[18,37]$, it is believed to be minor when compared with the strong particle reorientation and overall deformation caused by cone penetration.

\subsection{Production of thin sections}

Thin sections with a $30-\mu \mathrm{m}$ thickness and a size of $36 \times 22 \mathrm{~mm}$ were prepared from the oven-dried samples. This required the pore water to be replaced by a hardening material. Epoxy resin impregnation [10] was carried out in carefully carved smaller pieces or directly in the areas around the cone and shaft. A low viscosity resin was used and based on previous successful studies using resin impregnation of soil for fabric inspection, e.g., Fonseca et al. [7], it is believed that the soil microstructure was not disturbed by impregnation. Figure 4 shows the location of the thin sections for each test. For test MMT01, three thin sections were produced for locations around the shaft termed MMT01-S1, near the cone (MMT01-C1) and further away from the probe termed outside location (MMT01-O1) as shown in Fig. 4a. Similarly, five thin sections were produced for test MMT02 (Fig. 4b) and three for test MMT03 (Fig. 4c).

\section{Image acquisition and analysis}

\subsection{Microscopy equipment}

The thin sections were firstly inspected using polarized light microscope [19] to define specific areas of interest for detailed analysis by EPMA. A JEOL JXA-8500F Electron Probe Micro-Analyzer (EPMA) was used to obtain the backscattered electron images from the specific areas defined in the thin sections. These areas are marked with black dots for each thin section presented in Fig. 4. The areas are distributed according to the deformation zones observed by Paniagua et al. [27] and termed with the name of the test followed by the location, e.g., sample MMT01S1-1 is from test MMT01 and from region 1-1 around the shaft (S). The EPMA images representing each area have a size of 854 by 896 pixels. The images have a spatial resolution of $0.4 \mu \mathrm{m} / \mathrm{pixel}$; this allows a clear identification of the constituent grains and pore spaces.

\subsection{Porosity analysis}

EPMA imaging is based on the principle that atoms with a higher atomic number, $\mathrm{Z}$, are strongly scattered. The EPMA images are therefore obtained based on the composition of the material, which is represented in the image (gray scale image) by the different color of the pixels. The distribution of the number of pixels as a function of their 


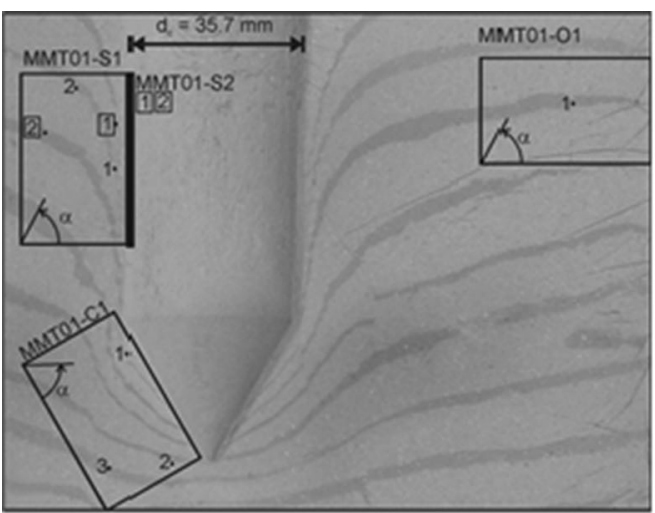

(a)

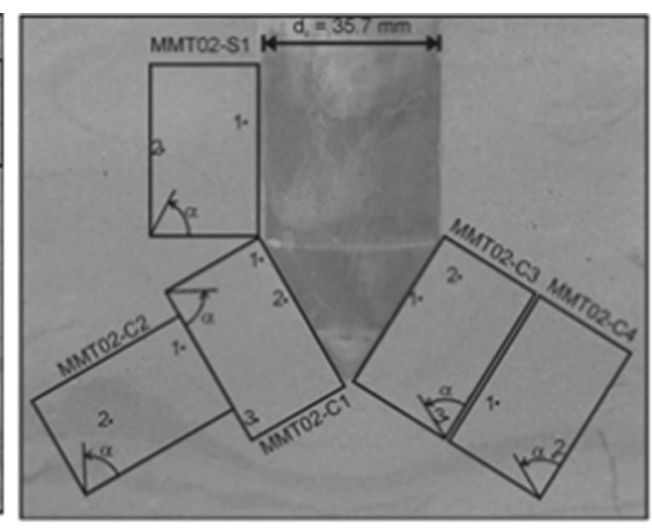

(b)

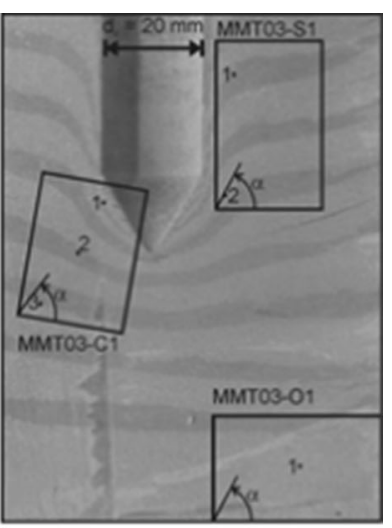

(c)

Fig. 4 Location of thin sections in the specimens studied: a MMT01, b MMT02 and c MMT03. The angle $\alpha$ indicates the reference plane for measuring the with where EPMA images

color or pixel intensity level is known as intensity histogram. The images considered in this study are composed of two main phases: the solid phase (grains) and the void space. Thus, the typical histogram takes the form of a bimodal distribution in which the pixel intensities are clustered around two well distinct values. In order to calculate the porosity or void ratio values, the gray scale images were converted into binary images where the pixels representing the solid or grains were attributed a value of 1 and the pixels representing the void space a value of 0 , according to their intensities relative to a threshold value. Otsu's method [24] was used for the image thresholding, which consists in clustering the pixels into two classes such that their intra-class variance is minimized [10]. The algorithm has been implemented in ImageJ $1.48 \mathrm{~g}$ [31]. The void ratio value for each region/image was obtained by dividing the number of pixels with value 0 by the number of pixels with value 1 (i.e., void/solid).

\subsection{Granular analysis}

As shown in Fig. 2, silt grains are irregular in shape, and their shape is largely controlled by the crystal structure of the constituent minerals. Based on the overall shape, the grains can be classified into either bulky or flaky grains. In order to investigate the characteristics of the grains, in particular, their orientation based on the major axis orientation, it is necessary to identify the individual grains within the solid phase, i.e., to segment the image. Watershed techniques are commonly used to segment images of sand, the characteristics of this silt, however, add further challenges to the segmentation process. In particular, the presence of fines and the diverse grain shapes ranging from very elongated, needle-like grains to convex large bulky particles, and the different mineralogical composition of the grains originates very distinct intensity values representing the solid phase in the images. In order to overcome these challenges, a multilevel intensity segmentation technique was developed in this study. This automated process represents a large improvement when compared with the manual and time-consuming technique used in Paniagua et al. [28]. In order to facilitate the image processing, grains defined by less than 30 pixels (approximately diameter of $2 \mu \mathrm{m}$ ) were removed and assumed that their orientation is not relevant for this analysis. This corresponds to the clay fraction and represents less than $2.5 \%$ of the total grains. The process of segmentation consisted of (1) filtering the solid phase with similar intensity values and (2) applying a series of morphological operations consisting of eroding and dilating the edges of the grains in order to associate with each grain a unique intensity value or grain's id. The MATLAB image processing toolbox (mathworks) was used.

Principal component analysis (PCA) was applied to determine the orientations of the major and minor axes for each grain, the principal axes of inertia. PCA is applied to the cloud of points/pixels defining each individual grain given by the $(x, y)$ coordinates (details can be found in Fonseca et al. [8]). The orientation of each grain (i.e., angle $\alpha$ ) is given by the vector describing the orientation of the major axis of the grain (Fig. 7a). Knowing the principal axis orientations an orthogonal rotation was applied to the voxel coordinates to rotate each particle so that its principal axes of inertia were parallel to the Cartesian axes. The major (a) and minor (c) dimensions of the particle were calculated, respectively, as : $a=\max \left(x^{\mathrm{rot}}\right)-\min \left(x^{\mathrm{rot}}\right)$, $c=\max \left(y^{\mathrm{rot}}\right)-\min \left(y^{\mathrm{rot}}\right)$, where $x^{\mathrm{rot}}$ and $y^{i}$ are $1 \mathrm{D}$ arrays giving the particle's pixel coordinates following rotation. The two principal lengths of each grain, in microns, were obtained by multiplying the length, given in pixels, by the size of each pixel (in this case of $0.4 \mu \mathrm{m}$ ). 
The classification of each grain into flaky or bulky type was done using the shape descriptor that measures the aspect ratio (AR) or elongation, obtained by the ratio between the lengths of the minor and the major axes in each grain (e.g., $\mathrm{AR}_{\text {sphere }}=1$ ). Grains were classified as bulky grains if $\mathrm{AR} \geq 0.5$ and flaky if $\mathrm{AR}<0.5$. Although the classification of the grains is based on $2 \mathrm{D}$ projections without information on the third dimension, the drawbacks of this simplification are minimized thanks to the distinct 'flaky' structure of the flaky grains. In other words, flaky grains tend to have elongated shapes with one dimension much greater than the two other ones (needle-like shape). Thus, unless a flaky grain is analyzed in a plane perfectly orthogonal to its major axis length, the large difference between the lengths of the two visible axes, enables its identification.

\section{Statistical distribution of grains orientation}

Oda [22] introduced the term 'orientation fabric' to refer to the magnitude and orientation of the preferred orientation of the major axes of the particles. In order to describe fabric, Oda et al. [23] quantifies the anisotropy resulting from the distribution of the shapes and orientations of particles. The orientation of the long axis data usually comprises a large dataset of vectors, so it must be statistically analyzed in order to provide meaningful measures of its distribution. Two approaches are used here to quantify fabric, the fitting of curves to histograms or rose diagrams and the fabric tensor approach.

\subsection{Histograms and curve fitting approaches}

For a given set of vectors, an effective way to visualize its distribution is by creating histograms or rose diagrams. In these plots, the vectors are 'binned' into an interval of selected size and represented as a segment whose length is proportional to the number of grains orientated within the angle defining the bin limits. The angle used in these histograms is measured from the lower boundary plane of the thin section (not always coincident with the horizontal plane as shown in Fig. 4). Curve fitting of the vectors distribution using a Fourier series [33] provides an effective way to describe the bias in the distribution.

\subsection{Fabric tensor and eigenvalue analysis}

The fabric tensor is commonly used to describe the preferred orientation of a dataset of vectors and its associated intensity. It takes generally the form of a second order symmetric tensor. Following Satake [34], the fabric tensor definition used here is:
$\Phi_{i j}=\frac{1}{N} \sum_{k=1}^{N} n_{i}^{k} n_{j}^{k}$

where $N$ is the total number of vectors in the system, $n_{i}^{k}$ is the unit orientation vector along direction $i$ and $n_{j}^{k}$ is the unit orientation vector along direction $j$.

An alternative definition of fabric tensor that considers both particle shape and particle orientation introduced by Oda et al. [23] and used in Fonseca et al. [8], is given by:

$\Phi_{i j}^{p a r t}=\frac{1}{\lambda} \sum_{k=1}^{N p} T_{k i}^{p} T_{l j}^{p} S_{i j}$

where $N_{p}$ is the number of particles and $T_{i j}$ is the orientation tensor for particle $p$ that can be understood as follows. For a given point on the particle with coordinates $x_{i}$ in a Cartesian coordinate system centered at the particle centroid, $x_{j}^{l p}=T_{i j} x_{i}^{p}$ gives the coordinates of the same point with reference to a local coordinate system also centered on the particle centroid but with axes aligned with the principal axes of inertia of the particle. The tensor $S_{i j}^{p}$ is defined as:

$S_{i j}^{p}=\left[\begin{array}{cc}a^{p} & 0 \\ 0 & c^{p}\end{array}\right]$

where $a^{p}$ and $c^{p}$ are the major and minor half lengths of the particle, respectively. The index $\lambda$ can be calculated by $\lambda=\sum_{p=1}^{N p}\left(a^{p}+c^{p}\right)$.

The principal fabric parameters can be obtained by eigenvalue decomposition of the fabric tensor. The eigenvectors of the fabric tensor give the orientation of the dominant directions of fabric anisotropy, and the eigenvalues $\left(\Phi_{1} ; \Phi_{3}\right)$ indicate the magnitude or the bias along these directions. The difference $\Phi_{1}-\Phi_{3}$ has been adopted here to describe the intensity of the anisotropy. The preferred orientation of the particle distribution can be described using the angle $\beta$ given by the eigenvector associated with the major eigenvalue of the fabric tensor [8]. This angular value is measured from the vertical plane, i.e., the plane perpendicular to the reference plane for angle $\alpha$.

\section{Results and discussion}

The fabric quantification is presented in terms of local void ratio distribution and using the angle $\beta$ and the anisotropy value given by $\Phi_{1}-\Phi_{3}$ to describe the distribution of the orientation vectors. Given the markedly difference in shape, it is expected the flaky and the bulky grains to respond differently to the rotation induced by shearing of the soil during cone penetration. In order to investigate the 
contribution of the flaky and of the bulky grains, the two grain types were analyzed separately.

The distribution of the local porosity values is presented as a plot of void ratio value against normalized distance $r / r_{c}$ and $x / r_{c}$, for the cone and shaft regions, respectively (Fig. 5). In these plots, $r_{c}$ is the cone radius, $\mathrm{r}$ is the distance measured from the intersecting point between the vertical cone axis and the horizontal shoulder axis, $\mathrm{x}$ is the horizontal distance from the cone vertical axis. Lower void ratio values can be observed near the cone face for $r /$ $r_{c}<1.75$, which coincides with the limits of the contraction zone identified by Paniagua et al. [27]. Beyond this point, the void ratio values are in general greater which suggests the presence of a dilation region. For the shaft region the void ratio values, with exception of test MMT03, tend to be lower than 0.95 and decrease as $x / r_{c}$ deceases, which suggests that compaction, in this region, is caused by the movement of the cone. These results suggest that the compaction effect along the shaft is more marked for the tests carried out using the larger diameter cone.

Table 2 summarizes the measured fabric parameters $\beta$ and anisotropy for the regions analyzed. The measurements are presented in terms of 'all grains' in the sample, 'bulky grains' only and 'flaky grains' only, respectively. The number of grains used in each the analysis is also indicated.

The degree of anisotropy of the fabric tensor given by $\Phi_{1}-\Phi_{3}$ is an indicator of the degree of scattering among the vectors of the grain orientation. Low anisotropy values indicate that the vectors are randomly oriented, in other words the granular system does not exhibit a clear preferential orientation. Three examples are presented to better illustrate cases of different anisotropy values (Fig. 6). Figure 6a represents sample MMT03-C1-2 for all grains with an anisotropy value of $A=0.08$ and an associated curve fitting showing a near circular shape. The curve fitting for the sample MMT02-C1-1 depicted in Fig. 6b shows a more elongated shape as an indication of a higher anisotropy value, in this case of $A=0.34$. An extreme case

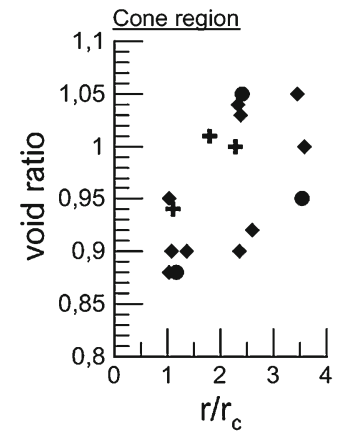

(a)

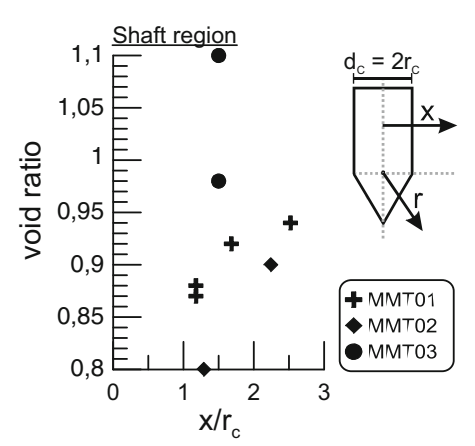

(b)
Fig. 5 Variation of void ratio values with the normalized distance a $r / r_{c}$ and $\mathbf{b} x / r_{c}$, for the different specimens investigated of a high anisotropic system is presented in Fig. 6c for sample MMT02-C1-1 using only flaky grains, in this case, the markedly orientation of the grains is translated by the anisotropy value of $A=0.48$ and by a more elongated shape of the rose plot. The orientation of elongated, anisotropic distributions, or the predominant particle alignment of the system, can be characterized by the angle $\beta$. In an isotropic distribution, however, the particles tend to align in random directions and the angle $\beta$ becomes less meaningful.

Figure 7 shows the distribution of the particle orientation vectors (given by angle $\alpha$ ) using rose diagrams. The bins of the histograms are shaded by the AR value of the respective vectors so that one can associate orientation to shape or grain type. Since the orientation of each individual particle does not have a specific direction, only half of the plane is considered. For the two regions located farther from the probe's zone of influence, it can be observed that for the sample MMT01-O1-1 the distribution of the orientation vectors show only a slight bias of horizontally oriented vectors while for the sample MMT03-01-1, a clear predominance of horizontally oriented vectors can be observed. This bias in the orientation of the grains is believed to be associated with the deposition process of the grains and the tamping used during sample preparation, which contributes to the settling of the grains under their most stable position, i.e., with the longest axis along the horizontal plane. In addition, these results also suggest that the top load of $40 \mathrm{kPa}$ used in test MMTO3 contributes to intensify this preferential realignment, when compared to the tests were no top load was used (MMTO1). In both cases, near horizontal positions are associated with more elongated grains (darker shading). Referring to Table 2, for all grains in the sample MMT03-O1-1, the predominant realignment of the grains is quantified by an anisotropy value of 0.26 for the flaky grains, 0.13 for the bulky and an overall value of 0.19 . The orientation of the principal fabric given by angle $\beta$ shows values greater than $80^{\circ}$, i.e., almost horizontal. For the sample MMT01-O1-1, the anisotropy is significantly lower, values of $0.07,0.02$ and 0.04 were measured for flaky, bulky and all grains, respectively. The principal fabric orientation value of $83^{\circ}$ for the flaky and of $67^{\circ}$ for the bulky was measured which suggests that the flaky grains are responsible for the bias in the angular distribution of the vectors.

Figure 8 illustrates the distribution of the particle orientation vectors for three samples positioned near the shaft, and one sample was taken from each test. Both the MMT01-S1-1 (Fig. 8a) and MMT02-S1-1 (Fig. 8b), samples are located on the left-hand side of the shaft (negative $\beta$ values) while MMT03-S1-1 (Fig. 8c) is located on the right-hand side (positive $\beta$ values). For the three cases, it can be seen that the grains tend to realign toward the 
Table 2 Information on the samples analyzed

\begin{tabular}{|c|c|c|c|c|c|c|c|c|c|c|}
\hline \multirow[t]{2}{*}{ Sample } & \multirow{2}{*}{$\begin{array}{l}r / r_{c} \\
x / r_{c}\end{array}$} & \multicolumn{3}{|c|}{ All grains } & \multicolumn{3}{|c|}{ Bulky grains } & \multicolumn{3}{|c|}{ Flaky grains } \\
\hline & & $\Phi_{1}-\Phi_{3}$ & $\beta\left({ }^{\circ}\right)$ & No. & $\Phi_{1}-\Phi_{3}$ & $\beta\left({ }^{\circ}\right)$ & No. & $\Phi_{1}-\Phi_{3}$ & $\beta\left(^{\circ}\right)$ & No. \\
\hline \multicolumn{11}{|l|}{ MMT01 } \\
\hline O1-1 & 4,90 & 0.04 & 80 & 897 & 0.02 & 67 & 464 & 0.07 & 83 & 433 \\
\hline S1-1 & 1,18 & 0.14 & -41 & 1012 & 0.09 & -51 & 458 & 0.19 & -36 & 554 \\
\hline S1-2 & 1,68 & 0.16 & -47 & 872 & 0.07 & -74 & 381 & 0.25 & -41 & 491 \\
\hline S2-2 & 2,52 & 0.22 & 55 & 1025 & 0.10 & 59 & 464 & 0.33 & 54 & 561 \\
\hline S2-1 & 1,18 & 0.19 & 22 & 923 & 0.07 & 32 & 366 & 0.27 & 19 & 557 \\
\hline $\mathrm{C} 1-3$ & 2,28 & 0.22 & 39 & 756 & 0.12 & 46 & 311 & 0.29 & 37 & 445 \\
\hline \multicolumn{11}{|l|}{ MMT02 } \\
\hline S1-1 & 1,29 & 0.22 & -9 & 746 & 0.13 & -9 & 354 & 0.31 & -9 & 392 \\
\hline S1-2 & 2,24 & 0.20 & -75 & 1000 & 0.11 & -66 & 432 & 0.28 & -78 & 568 \\
\hline $\mathrm{C} 2-2$ & 3,59 & 0.11 & -43 & 1443 & 0.05 & -32 & 651 & 0.17 & -45 & 792 \\
\hline C1-1 & 1,08 & 0.34 & -87 & 1320 & 0.16 & 89 & 587 & 0.48 & -86 & 733 \\
\hline C1-2 & 1,03 & 0.34 & 73 & 911 & 0.18 & 77 & 306 & 0.43 & 73 & 605 \\
\hline C1-3 & 2,38 & 0.22 & 54 & 1059 & 0.15 & 61 & 519 & 0.30 & 51 & 540 \\
\hline \multicolumn{11}{|l|}{ МMT03 } \\
\hline O1-1 & 6,44 & 0.19 & 85 & 1009 & 0.13 & 89 & 497 & 0.26 & 82 & 512 \\
\hline S1-1 & 1,50 & 0.24 & 37 & 1078 & 0.15 & 38 & 561 & 0.36 & 36 & 517 \\
\hline S1-2 & 1,45 & 0.28 & 43 & 1139 & 0.15 & 46 & 581 & 0.42 & 41 & 558 \\
\hline C1-1 & 1,17 & 0.35 & -72 & 875 & 0.25 & -71 & 425 & 0.44 & -72 & 450 \\
\hline C1-2 & 2,41 & 0.08 & -86 & 856 & 0.03 & 63 & 390 & 0.14 & -82 & 466 \\
\hline C1-3 & 3,54 & 0.09 & -78 & 1034 & 0.08 & -55 & 535 & 0.15 & 90 & 499 \\
\hline
\end{tabular}

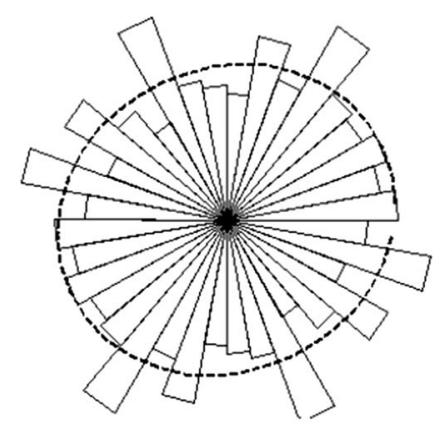

(a)

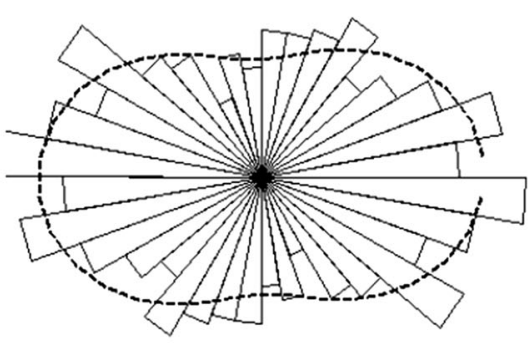

(b)

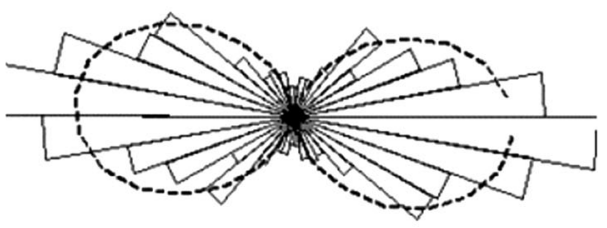

(c)

Fig. 6 Illustration of the fitting approach from a near isotropic distribution of grains orientation to more anisotropic cases: a MMT03-C1-2 $A=0.08$ (all grains), b MMT02-C1-1 $A=0.34$ (all grains), c MMT02-C1-1 $A=0.48$ (flaky grains)

direction of the shaft, and this phenomenon is stronger for the MMT02 test with a top pressure of $40 \mathrm{kPa}$ and a diameter of $35 \mathrm{~mm}$. This observation is also supported by the measured angle of the principal fabric: $\beta=-41^{\circ}$ (MMT01-S1-1), $\beta=-9^{\circ}$ (MMT02-S1-1) and $\beta=37^{\circ}$ (MMT03-S1-1). As observed before, the predominant orientation of the grains in the sample is associated with the more elongated or flaky grains, represented by the darker bins in the rose plots. A good agreement is found between the orientation of the grains described in the rose diagrams and the orientation of the deformed dyed layers in the images presented in Fig. 4, e.g., comparing Fig. 8a with Fig. 4a for the region near the shaft.

The clear realignment of the particles to positions where their longest axes lie near parallel to the cone face is shown in Fig. 9 for the sample MMT02-C1-1. In this case, the thin section is oriented parallel to the cone face, which constitutes the reference for measuring $\alpha$, in other words the predominant 'horizontal' orientation observed in these plots is along the cone face. The distribution of the vectors 

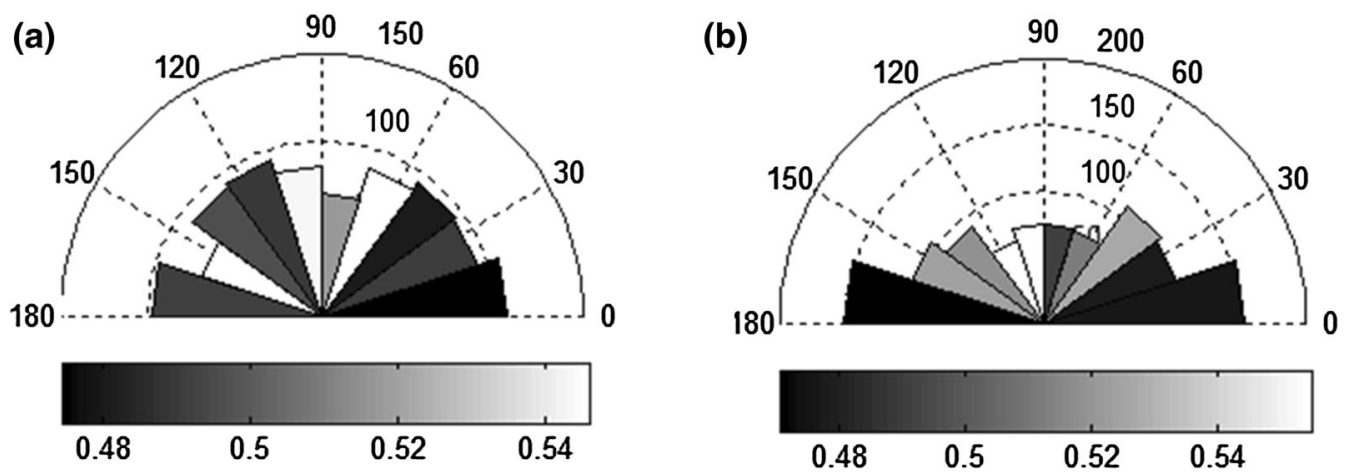

Fig. 7 Rose diagrams of particle orientations for all grains in the sample for locations a MMT01-O1-1, b MMT03-O1-1 (outside)
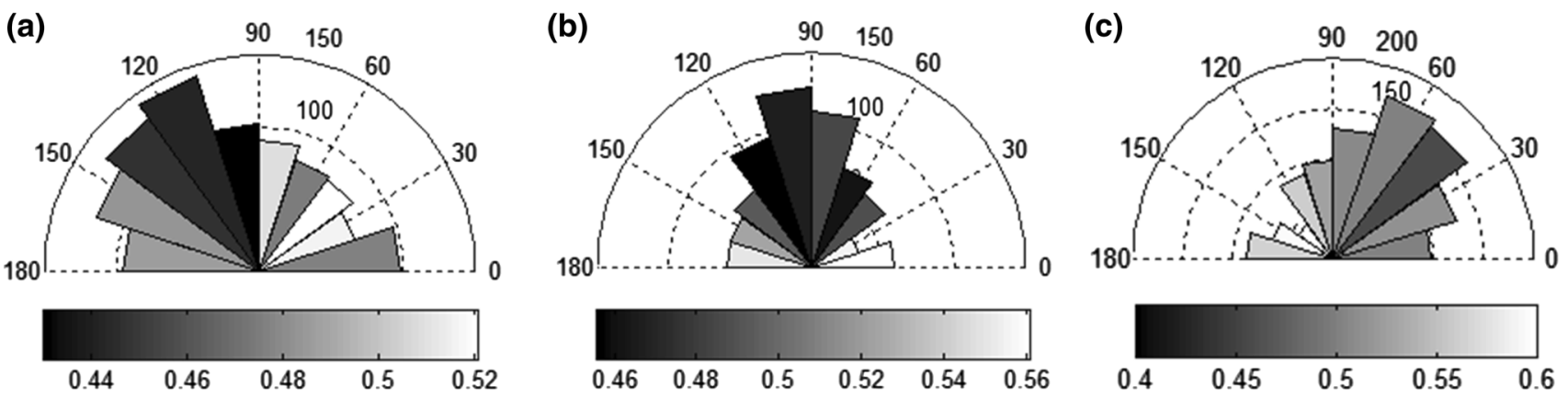

Fig. 8 Rose diagrams of particle orientations for all grains in the sample for locations a MMT01-S1-1, b MMT02-S1-1, c MMT03-S1-1, for the shaft region
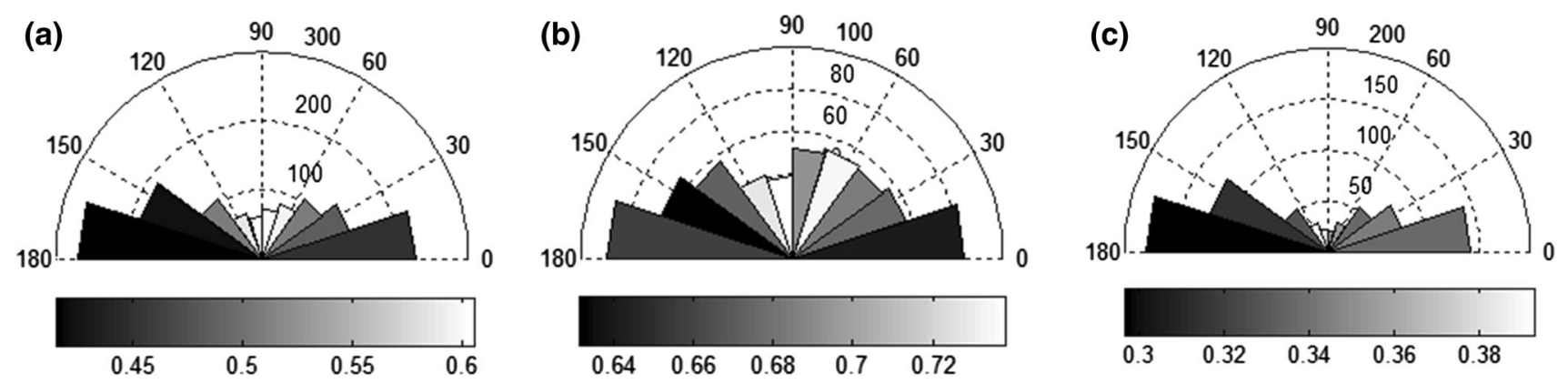

Fig. 9 Rose diagrams of particle orientations for location MMT02-C1-1 for a all grain, b bulky grains, $\mathbf{c}$ flaky grains, for the cone region

for all grains in the sample is presented in Fig. 9a, and the distribution for the bulky and flaky grains is depicted in Fig. 9b, c, respectively. The bias in the distribution is clearly greater for the flaky grains as shown in the distribution presented in Fig. 9c and from the darker shading (i.e., lower AR) of the horizontal bins in Fig. 9a. These observations illustrate the effect of the cone's penetration on the bulky and flaky grains, respectively, for test MMT02. Also making use of the anisotropy values given in Table 2, it can clearly be seen that the flaky grains $\left(\Phi_{1}-\Phi_{3}=0.48\right)$ are more prone to realign when compared to bulky grains $\left(\Phi_{1}-\Phi_{3}=0.16\right)$.

Figure 10 shows the evolution of the global orientation of the grains as the distance to the cone's face increases, the samples used are from test MMT03. Similar to the observation for test MMT02, the grains tend to realign along the face of the cone in particular the more elongated grains, as shown in Fig. 10a. As the distance to the cone increases this trend becomes less pronounced and the number of grains with arbitrary orientations increases (Fig. 10b, c). The anisotropy values measured, from Table 2, were of 0.35 for the region near the cone (MMT03-C1-1); lower values of 0.08 and 0.09 were measured for the regions MMT03-C1-2 and MMT03-C1-3 located at some distance from the cone's face.

Further insights into the distribution of the anisotropy values around the cone can be gained from the plots presented in Fig. 11. A clear decrease in anisotropy as we 

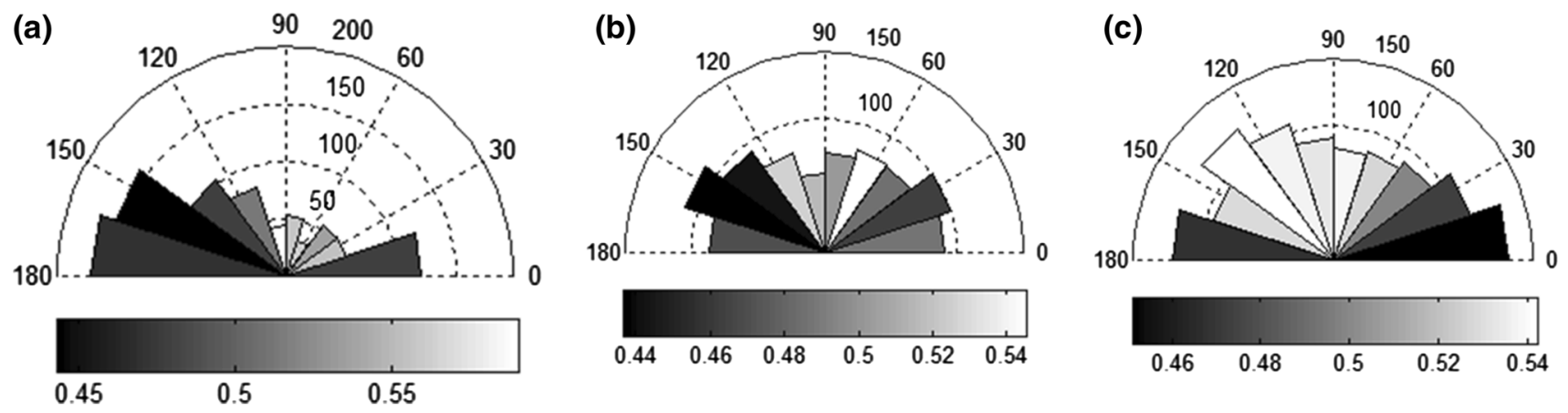

Fig. 10 Rose diagrams of particle orientations for all grains in the sample for locations a MMT03-C1-1, b MMT03-C1-2, c MMT03-C1-3, for the cone region. Shading indicates average aspect ratios of particles oriented within each angular bin
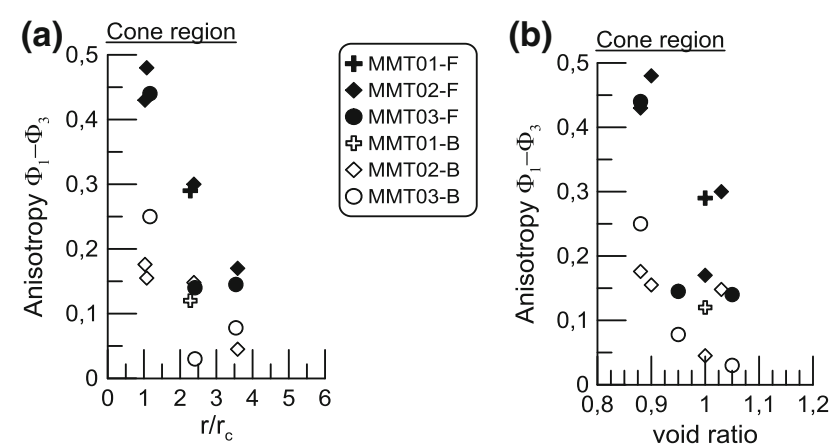

Fig. 11 Distribution of the anisotropy values as a function of a $r / r c$ and $\mathbf{b}$ void ratio for flaky (F) and bulky (B) grains in the cone region

move away from the cone face, i.e., as $r / r_{c}$ increases can be observed in Fig. 11a and this holds true for both flaky and bulky grains (represented by solid and hollow markers, respectively). It is shown here that the anisotropy values are able to provide a good quantification of the preferential alignment of the grains parallel to the cone's face. The distribution of anisotropy with void ratio (Fig. 11b) shows again a clear trend with higher anisotropy values occurring for regions with lower void ratio. In other words, the better alignment of the grains can be linked to contractive zones, whereas dilative regions are associated with grains arranged in more random orientations.

It is interesting to note that for the shaft region there is a more evident difference between the anisotropy values between the bulky and the flaky grains, as shown in Fig. 12a, b. The distribution of the anisotropy values against the distance from the shaft $\left(x / r_{c}\right)$ is, however, more complex to interpret, since the soil deformation in this zone is a function of not only the horizontal distance from the shaft but also of the vertical position along the shaft.

The fabric tensor parameters obtained from the formulation that accounts for the shape of the particles $\left(\Phi^{\text {part }}\right)$ were compared with the ones from the general formulation. For all samples, the anisotropy $\Phi_{1}^{\text {part }}-\Phi_{3}^{\text {part }}$ values were significantly lower than $\Phi_{1}-\Phi_{3}$. Since for the $\Phi^{\text {part }}$ formulation the orientations of the major and minor axes are
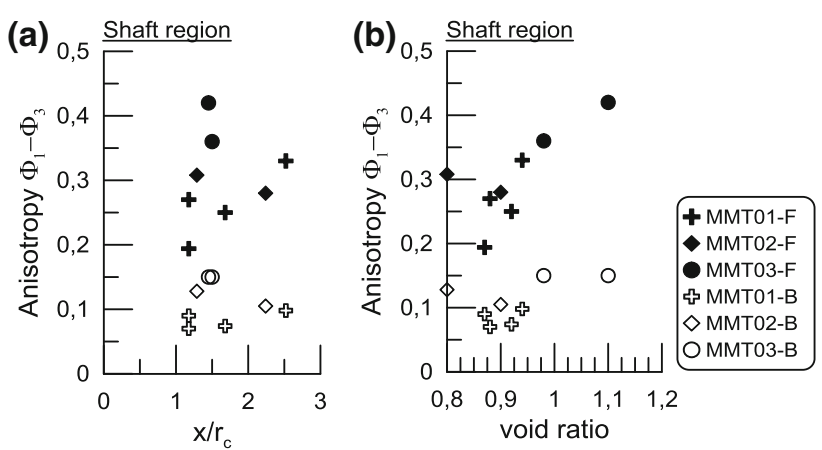

Fig. 12 Distribution of the anisotropy values as a function of a $x / r_{c}$ and $\mathbf{b}$ void ratio for flaky (F) and bulky (B) grains in the cone region

Table 3 Comparison of the angles $\beta$ and $\beta^{\text {part }}$ obtained from the general formulation of the fabric tensor, $\Phi$, and the $\Phi^{\text {part }}$ formulation, respectively

\begin{tabular}{llrr}
\hline Sample & $r / r_{c} x / r_{c}$ & $\beta\left(^{\circ}\right)$ & $\beta^{\text {part }}\left({ }^{\circ}\right)$ \\
\hline MMT01 & & & \\
S2-2 & 252 & 55 & 82 \\
S2-1 & 118 & 22 & -8 \\
MMT02 & & & \\
S1-2 & 224 & -75 & -84 \\
S1-1 & 129 & -9 & 0 \\
C1-1 & 108 & -87 & -83 \\
MMT03 & & & \\
S1-1 & 150 & 37 & 9 \\
S1-2 & 145 & 43 & 10 \\
\hline
\end{tabular}

weighted by their respective lengths, it will, in principle, provide a more accurate description of the fabric. However, when used to assess the degree of anisotropy the results seem to be affected by the presence of large grains with similar lengths along the major and minor axes (less obvious preferred orientation), which weakens the global trend given by the elongated grains. Despite this observation, when analyzing the fabric orientation given by the parameter $\beta^{\text {part }}$ the results demonstrate a good ability to 


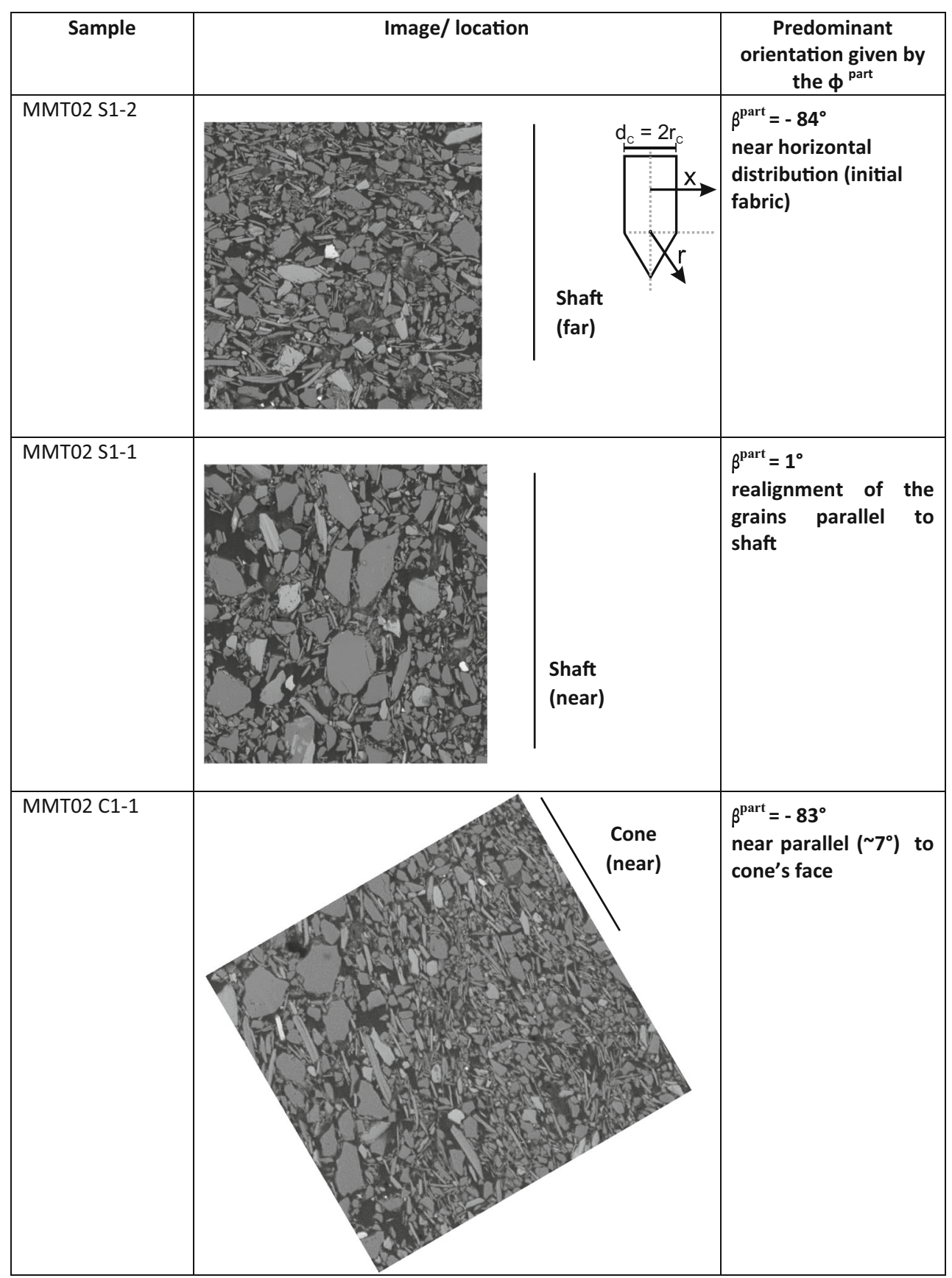

Fig. 13 a Selected EPMA images to illustrate the deformation patterns induced in the soil by the penetration of the cone and the associated $\beta^{\text {part }}$ values

quantify the general trend of the grains orientation. Table 3 shows the comparison of the $\beta$ values obtained using the general fabric tensor formulation and $\beta^{\text {part }}$ for selected samples. By comparing the values presented in Table 3 with the images from Fig. 13, one can see that $\beta^{\text {part }}$ can capture well the overall trend of grains orientation: (1) grains have a preferential horizontal orientation in regions away from the cone $\left(\beta \approx 80-90^{\circ}\right),(2)$ the grains orient parallel to the shaft in the near-to-shaft regions
( $\beta \approx 0-10^{\circ}$ ) and (3) grains realign parallel to the cone's face ( $\beta \approx 80-90^{\circ}$, image section parallel to cone face).

\section{Behavior across the scales}

The measurements of the local porosity have shown good agreement with the maps of volumetric strain obtained from previous 3D-DIC analysis, and these data were 


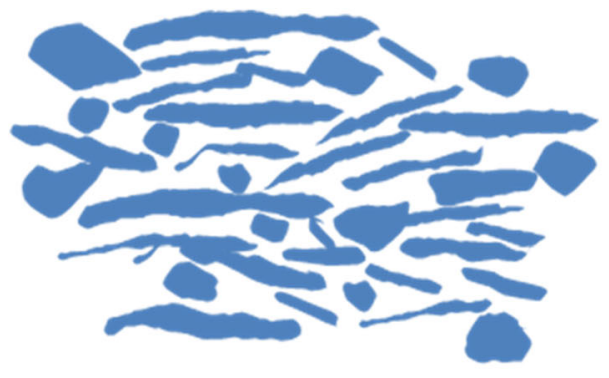

(a)

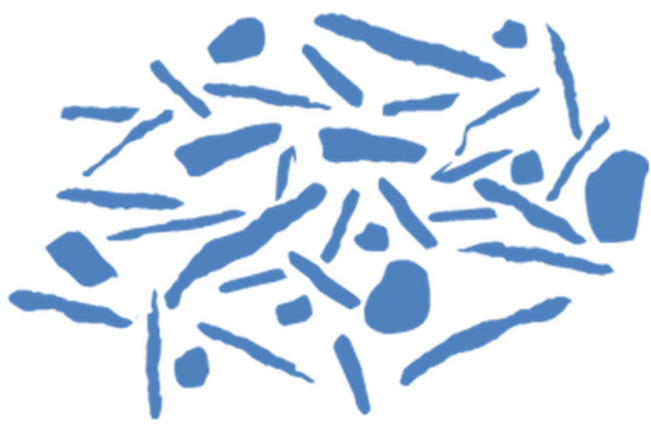

(b)

Fig. 14 Schematics of two soil fabric types formed following cone penetration: a closed-fabric region with the grains realigned along a preferred orientation forming a compacted zone and $\mathbf{b}$ an open-fabric where the grains are arranged with their major axis along random orientations creating large voids within them

(a)
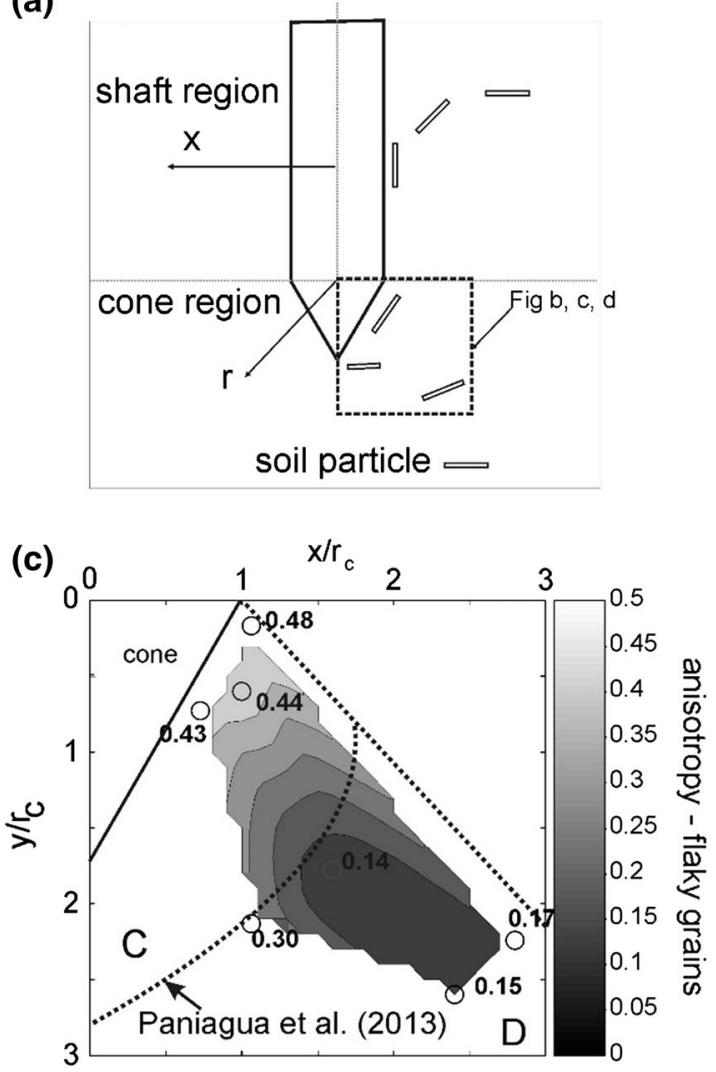

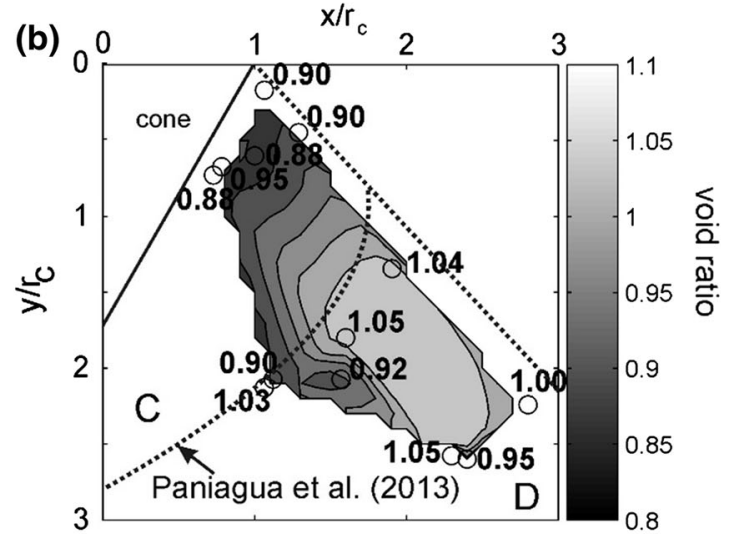

(d)

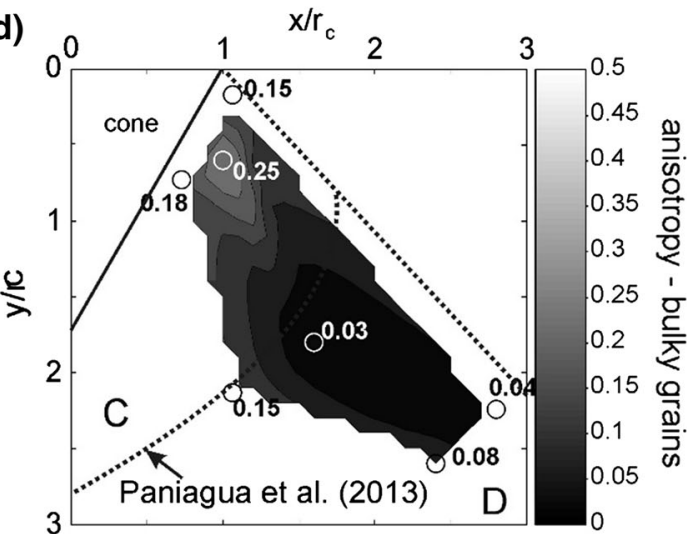

Fig. 15 a Schematic representation of the kinematics of deformation during CPTU after the present microstructural study. b Comparison of the extension of the influence zone around the cone proposed by Paniagua et al. [27] and the results from the present analysis for a sample with top pressure. A cubic interpolation method has been applied to obtain the shading in void ratio. C: compaction and D: dilation

combined with the fabric measurements to provide a better understanding of the grain-scale phenomena underlying the macro-scale response from the tests. It is shown here that the movement of the cone causes the grains to rotate and this phenomenon is particularly relevant given the large aspect ratios observed for the larger of the grains. While along the shaft the grains appear to align with their major axes parallel to the cone shaft, for the cone area the mechanisms taking place are more complex. Immediately near the cone's face the grains also align parallel to this surface forming a closed-fabric, or compacted fabric, with simultaneously high anisotropy and low porosity values (Fig. 14a). In the surrounding regions, however, more complex mechanisms of soil displacement create regions where grains reorient along random patterns that cause poor alignment of the grains and low anisotropy values. 
The fabric in these regions comprises grains oriented along multiple directions forming large voids within, in other words, dilative areas (Fig. 14b). Drainage in the soil mass is expected to take place from the compacted areas to the dilative ones. The interaction between the compressive and the dilative zones influences the distribution of pore pressures during penetration and thus, the partial drainage behavior of the material. Local drainage on the shear zone and its effect on pore pressure gradients are discussed in Atkinson and Richardson [3] for clay.

A schematic of the deformation patterns observed in the tests analyzed here is depicted in Fig. 15a. Figure 15b, c, d provides a comparison of the compressive and dilative zones observed by Paniagua et al. [27] with the values of void ratio and anisotropy extracted from the fabric tensor analysis. One can see that the limit between the compaction and dilative zone is near a void ratio value of 1.0 and anisotropy value of 0.15 for flaky grains and 0.05 for bulky grains, respectively. Higher anisotropy and lower porosity values are observed in the compaction zone, and lower anisotropy and higher porosity values are observed in the dilative zone.

The patterns of grain-scale deformation observed here were similar for the tests carried out using different cone sizes and different top pressure values. It is suggested, however, that the extension of the compaction and dilation zones formed near the cone tip depends on the initial effective stresses surrounding the penetrating probe. A stronger realignment of the grains along a preferred orientation was observed for the tests carried out under a surcharge (MMT02 and MMT03). These observations complement the findings from the tests carried out at different rates of penetration [29].

\section{Conclusions}

This study presents important insights into the deformed fabric following cone penetration in silt and the way the macroscopic response if affected by the newly formed fabric. The results here presented demonstrate the ability of the fabric tensor of the particle orientation vectors, in particular, the parameters anisotropy and the orientation of the major eigenvector, to capture the changes in fabric. The major eigenvector provides the preferential orientation of the grains for the various regions around the probe. The distribution of the local porosity from the analysis of the thin sections seems to agree well with the volumetric behavior obtained from the 3D-DIC analysis and, in particular, with the previously identified zones of dilation and contraction. The remarkable contribution of this study is that it provides a means of relating the formation of zone with different volumetric response to the fabric of the material in particular the statistical orientation of the grains traduced by the anisotropy value, i.e., the difference between the major and minor eigenvalues of the fabric tensor. The transitional nature of silt and the coexistence of grains with distinct morphologies both in terms of grain size and grain shape, in particular the presence of needlelike shape grains originates unique extreme types of soil fabric: (1) an 'open-fabric' where the grains reorient in random orientations creating large voids between them and (2) a 'closed-fabric' type in which the grains align along a well-defined preferred orientation forming a more compacted structure with small voids within. These two distinct soil patterns can be directly linked to drainage patterns and the formation of compaction and dilation zones that leads to the partially drained conditions observed in silt. In the case of a saturated soil, water may simply move locally from a compressive to a neighboring dilative zone, creating a short drainage path. The findings presented here support the value of combining observations from across the scales to improve our understanding of soil behavior. In particular, the fabric evolution of the geometrical rearrangement can be linked to the volumetric response of the material thus providing a more scientific explanation for the complex behavior observed for CPTU tests on silt.

Acknowledgements Workshop engineers F. Stæhli and T. Westrum at NTNU are greatly acknowledged for valuable help with construction of the testing apparatus. Engineer A. Mons $\varnothing y$ at NTNU prepared the thin sections. The EPMA scans were performed by Engineer K. Eriksen at NTNU.

Open Access This article is distributed under the terms of the Creative Commons Attribution 4.0 International License (http:// creativecommons.org/licenses/by/4.0/), which permits unrestricted use, distribution, and reproduction in any medium, provided you give appropriate credit to the original author(s) and the source, provide a link to the Creative Commons license, and indicate if changes were made.

\section{References}

1. Andò E, Hall SA, Viggiani G, Desrues J, Bésuelle P (2012) Experimental micromechanics: grain-scale observation of sand deformation. Géotech Lett 2(3):107-112

2. ASTM D2487-10 (2010) Standard practice for classification of soils for engineering purposes (Unified Soil Classification System). ASTM International, West Conshohocken, PA

3. Atkinson JH, Richardson D (1987) The effect of local drainage in shear zones on the undrained shear strength of over consolidated clay. Géotechnique 37(3):393-403

4. Bradshaw AS, Baxter CDP (2007) Sample preparation of silts for liquefaction testing. Geotech Test J 30(4):324-332

5. British Standard (1990) BS 1377-2 Methods of test for soils for civil engineering purposes: classification tests

6. Cho GC, Dodds J, Santamarina JC (2006) Particle shape effects on packing density stiffness and strength natural and crushed sands. ASCE J Geotech Geoenviron Eng 132(5):591-602 
7. Fonseca J, O'Sullivan C, Coop M, Lee PD (2012) Non-invasive characterization of particle morphology of natural sands. Soils Found 52(4):712-722

8. Fonseca J, O'Sullivan C, Coop M, Lee PD (2013) Quantifying evolution soil fabric during shearing using directional parameters. Géotechnique 63(6):487-499

9. Fonseca J, O’Sullivan C, Coop M, Lee PD (2013) Quantifying evolution soil fabric during shearing using scalar parameters. Géotechnique 63(10):818-829

10. Gylland A, Rueslåtten H, Jostad HP, Nordal S (2013) Microstructural observations shear zones in sensitive clay. Eng Geol 163:75-88

11. Highway Research Board (1945) Report of the committee on classification of materials for subgrades and granular type roads 25: $375-388$

12. Kim Y (2012) Properties of silt and CPTU in model scale. NTNU, Trondheim (MSc dissertation)

13. LeBlanc C, Randolph M (2008) Interpretation of piezocone in silt, using cavity expansion and critical state methods. In: Proceedings of the 12th international conference of international association for computer methods and advances in geomechanics (IACMAG), Goa, India

14. Long M, Donohue S, Hagberg K (2010) Engineering characterisation of norwegian glaciomarine silt. Eng Geol 110:51-65

15. Lunne T, Robertson P, Powell J (1997) CPT in geotechnical practice. Blackie Academic, New York

16. Lupini JF, Skinner AE, Vaughan PR (1981) The drained residual strength of cohesive soils. Geotechnique 31:181-213

17. Mitchell JK, Soga K (2005) Fundamentals of soil behavior. Wiley, Hoboken

18. Mitchell J, Soga K (2005) Fundamentals of soil behavior. Wiley, Hoboken

19. Nesse W (2011) Introduction to mineralogy. Oxford University Press, Oxford

20. Norsk Geoteknisk Forening (2011) Veiledning for symboler og definisjoner i geoteknikk: identifisering og klassifisering av jord. Melding 2

21. Nouguier-Lehon C, Cambou B, Vincens E (2003) Influence of particle shape and angularity on the behaviour of granular materials: a numerical analysis. Int J Numer Anal Method Geomech 27(14):1207-1226

22. Oda M (1977) Coordination number and its relation to shear strength of granular material. Soils Found 17(2):29-41

23. Oda M, Nemat-Nasser S, Konishi J (1985) Stress induced anisotropy in granular masses. Soils Found 25(3):85-97
24. Otsu N (1979) A threshold selection method from gray level histograms. IEEE Trans Syst Man Cybern 9(1):62-66

25. Ovando-Shelley E (1986) Stress-strain behaviour of granular soils tested in the triaxial cell doctoral dissertation. University of London, Imperial College London, London

26. Paniagua P, Gylland A, Nordal S (2012) Experimental study of deformation pattern around penetrating coned tip. In: Laloui L, Ferrari A (eds) Multiphysical testing soils-shales. Springer, Berlin, pp 227-232

27. Paniagua P, Andó E, Silva M, Nordal S, Viggiani G (2013) Soil deformation around penetrating cone in silt. Géotech Lett 3(4):185-191

28. Paniagua et al, (2014). Microstructural study of the deformation zones around a penetrating cone tip in silty soil. In: Proceedings of the international symposium on geomechanics from micro to macro (IS-Cambridge 2014), Cambridge

29. Paniagua P, Fonseca J, Gylland A, Nordal S (2015) Microstructural study of deformation zones during cone penetration in silt at variable penetration rates. Can Geotech J 52:1-11

30. Pena AA, Garcia-Rojo R, Herrmann HJ (2007) Influence of particle shape on sheared dense granular media. Granul Matter 9(3):279-291

31. Rasband W (2013) ImageJ 1.48 g, National Institutes of Health USA

32. Reite A (1990): Sør-Trøndelag fylke. Kvartærgeologisk kart M 1:250.000. Veiledning til kartet. Norges geologiske unders $\varnothing \mathrm{kelse}$ Skrifter 96:1-39

33. Rothenburg L, Bathurst RJ (1989) Analytical study of induced anisotropy in idealized granular materials. Géotechnique 39(4):601-614

34. Satake M (1982) Fabric tensor in granular materials. In: Vermeer and Luger (eds) Proceedings of the IUTAM symposium on deformation and failure of granular materials, Delft, Balkema, Amsterdam, 63-68

35. Shipton B (2010) The mechanics of transitional soils doctoral dissertation. Imperial College London, London

36. Sridharan A, Sivapullaiah PV (2005) Mini compaction test apparatus for fine grained soils. Geotech Test J 28(3):240-246

37. Tovey N, Wong K (1973) The preparation of soils and other geological materials for the SEM. In: Proceedings of international symposium soil structures, Gothenburg: 59-67

38. Yang S (2004) Characterization of the properties of sand-silt mixtures doctoral dissertation. Norwegian University of Science and Technology, Trondheim 